\title{
MAPEAMENTO DAS PESQUISAS SOBRE ROBÓTICA EDUCACIONAL NO ENSINO FUNDAMENTAL*
}

\section{MAPPING OF RESEARCHES ON EDUCATIONAL ROBOTICS IN ELEMENTARY SCHOOL}

\author{
Fernando da Costa Barbosa \\ Universidade Federal de Goiás \\ fcbarbosa@ufg.br \\ Crhistiane da Fonseca Souza \\ Universidade Federal de Goiás \\ crhisfsouza@gmail.com \\ Arlindo José de Souza Junior \\ Universidade Federal de Uberlândia \\ arlindoufu@gmail.com \\ Deive Barbosa Alves \\ Universidade Federal do Tocantins \\ deive@mail.uft.edu.br
}

RESUMO: A Robótica Educacional no Brasil tem ganhado força desde 2002, resultando em trabalhos de dissertação e teses em diferentes programas de pós-graduação. Nesse sentido, buscou-se então entender e fazer um levantamento das produções acadêmicas brasileiras, em especial voltadas para o Ensino Fundamental, produzindo assim um estado da arte. Para construir esse trabalho, concentram-se os esforços em produções que estavam online, tanto no banco da CAPES como na biblioteca nacional, fazendo um mapeamento de vinte oito produções em pouco mais de dez anos. Os resultados dessas pesquisas apontaram uma ramificação das atividades com materiais de robótica livre até proprietários (comerciais) para fins educacionais. Foi possível perceber a empregabilidade dos materiais para o ensino tanto de Matemática como de outras áreas conhecimentos, em sua maioria se apoiando em desenvolvimento de projetos de caráter investigativo.

PALAVRAS-CHAVE: robótica; estado da arte; ensino fundamental.

ABSTRACT: Educational Robotics in Brazil have gained strength since 2002, resulting in dissertation and thesis works in different postgraduate programs. In this sense, it was sought to understand and make a survey of the Brazilian academic productions especially focused on Primary Education, producing thus a state of the art. To build this work, efforts have been concentrated on online information from CAPES database and national library, obtaining a mapping in little more than ten years with twenty-eight productions. This research results point to a branch of activities with free robotics to owners (commercials) to educational purposes content. It was possible to notice the materials employability to teach Math and others subjects, in its majority, supporting itself in developing projects of

* Este trabalho foi escrito a partir da tese de doutorado de Barbosa (2016). 
investigative character.

KEYWORDS: robotics; state of art; Elementary School.

\section{Introdução}

O trabalho com Robótica Educacional (RE) tem nos últimos anos se destacado em diferentes níveis de ensino e mais trabalhos têm surgido como resultado das produções com robôs no contexto da escola. Parece um brinquedo novo que está em moda, mas que já possui longos anos de vida e experiência, os quais permitiram alcançar o sucesso atual. Apesar dessas fragmentações de informação, quando iniciamos nossos trabalhos com Robótica Educacional sempre surgiam as inquietações do que já se tinha de material produzido. Quais outros caminhos já foram percorridos e quais podemos ainda percorrer? Tínhamos a necessidade de saber mais; o iniciar por uma nova linha de pesquisa a princípio é um caminhar no escuro.

Essas motivações que nos levaram a conhecer mais sobre o que se tem desenvolvido no campo da Robótica Educacional são caracterizadas um estado da arte. A primeira motivação aconteceu em 2010 e 2011, quando as primeiras reflexões ficaram registradas em Barbosa (2011). Apesar dessa primeira investigação, faltava ainda um olhar mais profundo e minucioso, tanto que a partir de 2013 decidiu-se fazer esse estudo do conhecimento, buscando não os cinco últimos anos de trabalho de Robótica Educacional no Brasil, mas todas as dissertações e teses publicadas e disponíveis online no Brasil e que estivessem no banco da CAPES ou na Biblioteca Nacional. Assim, em 2016, em uma tese, desenvolvemos um estado da arte de um pouco mais de 10 anos de trabalhos referentes à Robótica Educacional no Brasil.

O recorte neste artigo versa sobre os trabalhos no Ensino Fundamental e foi escolhido devido à necessidade de analisar as diferentes possibilidades e perspectivas do trabalho com Robótica Educacional dentro de uma etapa da Educação Básica. É importante destacar que, desde 2005, o ensino fundamental passou a ter duração de nove anos e atende aos estudantes de seis a quatorze anos.

\section{Reflexões iniciais sobre a Robótica Educacional}

Gonçalves (2007, p. 21) afirma que "Seymour Papert foi pioneiro em utilizar a robótica para fins educacionais". São palavras fortes, mas Papert, no Massachusetts Institute of Technology (MIT), desenvolveu a primeira versão da linguagem de programação LOGO em 1968, contendo apenas a parte de processamento de listas. Depois, foram criados comandos como o girar e o andar de um robô (CURCIO, 2008, p. 25). Toda inspiração veio das tartarugas de William Grey Walter. Papert, através delas, construiu o software LOGO e elas também se tornaram plataformas físicas de aplicação do software. Essa trajetória mencionada por outros pesquisadores é entendida como um princípio do uso da robótica na educação. Segundo Pontes (2010), não se pode descartar que a atitude de Papert em unir LOGO e a tartaruga física é o ponto de start da robótica educacional, pois, sem essa atitude, um trabalho de cibernética, a robótica e a educação não se encontrariam tão cedo. 
Para Campos (2005), com o avanço da produção de microprocessadores e microcomputadores, a tartaruga mecânica sai de cena dando lugar apenas à tartaruga gráfica, presente no computador. A partir desse momento, o software LOGO começa a ser conhecido pelo mundo como aplicação na educação. Furletti (2010), ao contextualizar as tecnologias na educação no Brasil, confirma que a década de 1970 inicia-se com investimento em pesquisa na área da educação, principalmente em função da necessidade de capacitação científico-tecnológica para o desenvolvimento do Brasil. Pensando nessa intenção, as universidades focaram seus esforços na produção de softwares educacionais e sua utilização no contexto escolar. Nesse processo, a "Universidade Estadual de Campinas (UNICAMP), sustentada pelos pressupostos teóricos do construcionismo de Seymour Papert, desenvolve pesquisas utilizando a linguagem de programação LOGO" (FURLETTI, 2010, p. 33).

Percebe-se que o princípio das pesquisas de uso de computadores nas escolas, isto é, tecnologias computacionais, teve uma influência de Seymour Papert, que compartilhou suas experiências e saberes. Em consequência disso, a disseminação das ideias de robótica educacional foi feita inicialmente por ele em 1975. Curcio (2008, p. 23) ainda completa que em "1986, a Lego lançou robôs programados usando a linguagem LOGO e, em 1989, Seymour Papert se uniu à Lego. Em 1998, a empresa lançou a série Lego Mindstorms, com o modelo Robotics Invention System" (CURCIO, 2008, p. 23).

Essa parceria de Papert com a LEGO necessitou de uma versão de Logo própria para os kits de robótica. A versão utilizada nos kits LEGO Technic denomina-se TC Logo (STEFFEN, 2002, p. 8-9). Segundo Steffen (2002) e Campos (2005), esses kits da LEGO, desenvolvidos para uma função pedagógica, chegaram ao Brasil via universidade, para posteriormente chegar às escolas.

A partir desses fatos, percebe-se a importância de Seymour Papert na influência das pesquisas em tecnologias educacionais, quando veio apresentar seu software LOGO e, posteriormente, apresentar materiais para a robótica educacional. O ponto de origem é o MIT, e os pontos finais são UNICAMP ${ }^{1}, \mathrm{UFAL}^{2}$ e UFRGS ${ }^{3}$. A partir desses pontos finais, outros também surgiram, alguns se alimentando da fonte original e, com o passar dos anos, dos outros colegas brasileiros que pesquisaram sobre RE. As regiões que mais se desenvolveram nesse campo foram Sudeste, Sul e Nordeste. Aos poucos, as outras regiões começam a despontar com alguns trabalhos. Os

principais projetos de robótica educacional são iniciativas isoladas de universidades, prefeituras ou escolas particulares. A maioria das instituições utiliza kits padronizados, formado por hardware, software e material didático próprios. Algumas, em outra direção, adotam software livre e material reciclado para construção de robôs com diferentes níveis de complexidade (CURCIO, 2008, p. 23, grifos nossos).

Mesmo assim, acredita-se que as pesquisas e projetos trabalharam com um referencial muito comum: Seymour Papert. A partir de sua importância nas pesquisas no Brasil, na robótica educacional, e de ser um dos criadores do kit de robótica educacional

1 Universidade Estadual de Campinas (UNICAMP).

2 Universidade Federal de Alagoas (UFAL).

3 Universidade Federal do Rio Grande do Sul (UFRGS). 
da LEGO®, nada mais coerente e justo que seja uma referência ideológica e teórica, tendo em vista que integrar a tecnologia em prol do desenvolvimento do pensamento humano, é buscar "um fim à cultura que faz com que a ciência e a tecnologia sejam estranhas para a grande maioria das pessoas. Muitas barreiras culturais impedem as crianças de fazerem um conhecimento científico próprio" (PAPERT, 1980, p. 4, nossa tradução).

A máquina estaria contribuindo para a construção de uma nova cultura, um tipo de pensar e agir, como "mensageiros de ideias poderosas". No que diz respeito às ideias poderosas, Campos (2005), ao tocar nesse assunto, traduz e interpreta o termo powerful ideas, usado por Papert, como explosões de ideias. É importantes no que diz respeito a entender o significado, a origem das coisas, saber "os 'como' e 'porquês' por detrás de um conceito, ele não somente terá um melhor entendimento das informações, mas terá a habilidade de aplicar os conceitos em qualquer outro lugar" (CAMPOS, 2005, p. 60). Papert (1996) já dizia que mais importante que adquirir habilidades é saber usar aquilo que já conhecemos, ou seja, usar os recursos disponíveis de modo a transformar o mundo, criar, ser autor nesse processo. Aprender com o objeto.

A busca por ideias poderosas está atrelada a uma pedagogia da pergunta, mencionada e defendida por Paulo Freire em um de seus debates com Papert: "É por isso que eu defendo, junto com o chileno filósofo Fagundes, a pedagogia da pergunta e não da resposta. A pedagogia da pergunta é a que se baseia na curiosidade" (PAPERT, 1980, p. 1, tradução nossa).

Nessa filosofia de questionar, procurando por ideias poderosas, Papert (2000) atribui às tecnologias o caminho para se conseguir alcançar a construção dessas ideias. No discurso de Papert, é importante compreender que o principal está nas ideias. A tecnologia, o computador, é o meio pelo qual se pode simular, construir uma versão do mundo com a tecnologia, um micromundo de possibilidades de investigação, pesquisa, aprendizagem e ensino.

Papert nos deixa ideias poderosas para a construção de espaços de ensino que trabalhe com modelos, microrrepresentações do mundo em conexão com a tecnologia, a ciência e a construção de protótipos. É justamente na referência de Seymour Papert e seus companheiros de pesquisa e trabalho que surge a Robótica Educacional (RE). São diversas as interpretações e definições. Rocha (2006, p. 52), por exemplo, entende como a superação do processo de montar peças, que orienta num processo de mudança dos sujeitos envolvidos no ensino e aprendizagem, ou seja, o professor e o aluno ganham novos papéis, que sofrem "mudança de postura, diálogo, cooperação, metodologia, dúvida e indagação, além de significação".

Já Lopes (2008, p. 41) define RE "como um conjunto de recursos que visa ao aprendizado científico e tecnológico integrado às demais áreas do conhecimento, utilizando-se de atividades como design, construção e programação de robôs". Além disso, na visão de Campos (2005) a robótica educacional está relacionada a ambientes de aprendizagem. Para Curcio (2008, p. 9), é a potencialização dos meios tecnológicos. Percebe-se que a robótica até então é vista essencialmente como um recurso poderoso ao desenvolvimento cognitivo do aluno, capaz de ressignificar a forma de aprender os conhecimentos científicos.

Pode-se completar dizendo que, no processo de trabalho com robótica, aprende-se a discutir e a trabalhar em grupo, organizar-se, criar e comunicar, além de fortalecer 
outras características que nos tornam aptos a conviver e trabalhar em sociedade (MORAES, 2010; STEFFEN, 2002). Essa é a RE, um olhar sobre sua constituição histórica e caracterização. Compreendido isso, vejamos a seguir como essa semente plantada em nossa terra se desenvolveu, principalmente no Ensino Fundamental.

\section{Pesquisas sobre Robótica Educacional no Brasil}

Um dos primeiros trabalhos que encontramos online foi de Chella (2002), trabalho de mestrado, na pós-graduação de Engenharia de Programa de Engenharia Elétrica e da Computação da Unicamp, no qual propôs uma pesquisa que visava à implementação de um ambiente de robótica educacional, composto por aplicativos e componentes de hardware. Pela constituição de sua pesquisa já se pode perceber sua interpretação sobre o que seja robótica educacional: no corpo de sua dissertação é definida claramente como sendo "o ambiente constituído pelo computador, componentes eletrônicos, eletromecânicos e programa" (CHELLA, 2002, p. 23). Seu objetivo era explorar conceitos das diversas áreas de conhecimento dentro de "um contexto que estimule a multi e a interdisciplinaridade, dando-lhe o controle sobre a elaboração do seu próprio conhecimento" (CHELLA, 2002, p. 13).

Para tanto, foi construído todo um ambiente, constituído de um programa, linguagem SuperLogo, programa para comunicação remota, ou seja, telerrobótica. Em termos de hardware: kit RCX da LEGO ${ }^{\circledR}$ é a constituição de uma interface de hardware para robótica (IHR) para controle de servo motores e sensores. Todos esses elementos constituíam o "Ambiente de Robótica Educacional (ARE)" (CHELLA, 2002, p. 51). O ARE foi aplicado inicialmente com apenas um aluno da graduação de Mecatrônica, que estava desenvolvendo iniciação científica justamente com dispositivos robóticos e fazia estágio no NIED. Seu trabalho foi com o kit RCX da $L E G O \circledR$ e, segundo Chella (2002, p. 123), foi possível "testar hipóteses, projetar, desenvolver algoritmos e elaborar protótipos que posteriormente foram aplicados" em sua iniciação científica.

Após um teste inicial, outro grupo de pessoas que experimentou o ARE foi o de alunos de pós-graduação em informática aplicada à educação, que, utilizando a IHR, desenvolveu projetos, como, por exemplo: sobre os dinossauros (para explicar a relação da presa e predador), projeto pauta musical (uma relação com a arte e educação, buscando envolver a utilização de desenhos e gráficos que representassem notas musicais), projeto Emília (que resgatava as histórias de Monteiro Lobato com uma boneca robótica conectada e programada pelo SuperLogo) e projeto Energia Alternativa (que buscava explicar o funcionamento da fonte de energia eólica).

Outro grupo que trabalhou com o IHR foi o de alunos do Ensino Fundamental que também desenvolveu alguns projetos robóticos: controle do braço robótico, além da construção de uma máquina de refrigerante, robô "pega lixo", parque de diversão e mão robótica. Para finalizar, o ARE foi apresentado à telerrobótica na forma de uma oficina a parceiros de pesquisa do NIED, a OEA (Organização dos Estados Americanos) da Argentina.

Assim, a pesquisa de Chella (2002) contemplou a constituição de um ambiente de robótica e o aplicou a todas as instâncias de ensino, com alunos do Ensino Fundamental, 
graduação, pós-graduação e pesquisadores parceiros. Segundo o autor, através da RE foi possível contextualizar conceitos ensinados em sala de aula.

Tem-se nesse mesmo ano a produção de Steffen (2002), que desenvolveu uma dissertação sobre robótica educacional, pensando-a como um ambiente de aprendizagem e um recurso de comunicação. Em sua fundamentação teórica, abordou a comunicação na relação do desenvolvimento cognitivo, já que para ela a "Robótica define espaços de convivência humana, que promovem o educar pela comunicação, tendo como pano de fundo a valorização do cognitivo" (STEFFEN, 2002, p. 53).

Sua pesquisa foi construída a partir de sua experiência profissional, enquanto professora de Ciências e Robótica educacional em uma instituição de ensino particular da cidade de São Paulo, considerada, por ela, pioneira nos trabalhos com robótica. Assim, de toda sua experiência de cinco anos, foi filtrada e divulgada a análise de duas experiências que tinham sentido de trabalho com conhecimentos distintos, ou seja, uma das experiências partia do conteúdo científico de "alavancas", e buscou desenvolver protótipos para se discutir o assunto. Já a segunda experiência possuía uma intencionalidade mais lúdica, ou seja, competição de robôs que carregavam ovos, mas que, por trás da atividade, abordava conhecimentos científicos necessários a garantir o sucesso da situação-problema proposta na atividade. Essas experiências conduziram o aprendiz ao exercício de um diálogo criativo com as dúvidas e interrogações da atualidade, condição necessária para uma formação cidadã, um dos 'saberes' necessários para a vida (STEFFEN, 2002).

Dessa forma, a pesquisadora estabeleceu uma relação da ciência com a tecnologia, usou a tecnologia para ensinar ciência, "o ambiente de aprendizagem das aulas de Ciências, que antes serviam de modelo à Robótica, foi reestruturado. Robótica passou a ser referência para Ciências" (STEFFEN, 2002, p. 3). O conhecimento científico seria evidenciado a partir da robótica, ou seja, a mudança de direção metodológica.

Já Ortolan (2003) desenvolveu sua dissertação na Faculdade de Ciência da Computação da Universidade Federal de Santa Catarina. Sua pesquisa descreveu uma experiência construtiva com robótica educacional em um colégio da cidade de Cascavel, com alunos de $6^{\circ}$ e $7^{\circ}$ anos do Ensino Fundamental. Ela analisou as possibilidades de implementação de uma tecnologia na educação,

buscando sustentar a tese de que é possível aplicar um processo de aprendizagem com uso irrestrito de tecnologia, sem com isso desvincular da educação escolar a incumbência de formar um cidadão crítico e socialmente participativo (ORTOLAN, 2003, p. 3).

Como objetivo principal, a autora analisou o uso do software ROBOLAB - para controlar RCX do kit de robótica da LEGO - como uma ferramenta pedagógica a ser aplicada no sistema de ensino. Para fundamentar sua pesquisa, ela desenvolveu seu texto sobre o uso das "novas tecnologias" 4 na educação. Sua pesquisa apontou que o trabalho com robótica, no que se refere à programação dos dispositivos e trabalho com situações-problemas, resultou em reflexos positivos no desempenho dos alunos na escola, em termos de notas e de raciocínio lógico. Outros pontos também levantados estavam na criatividade, no desenvolvimento de lideranças, na forma coletiva de

4 Termo usado por Ortolan. 
trabalhar, no papel do professor nesse processo, o qual deve estimular mais que a construção de protótipos, as explicações científicas para cada uma das suas reações (ORTOLAN, 2003, p. 112).

Santana (2003) realizou uma pesquisa em robótica pedagógica com alunos do Ensino Fundamental do $6^{\circ}$ ao $9^{\circ}$ ano de uma instituição privada no turno oposto às aulas. Nesse trabalho, ela acompanhou a implantação da robótica como uma disciplina da matriz curricular da escola. As atividades foram com kit da LEGO ${ }^{\circ}$ Education. Havia apostilamento, mas no decorrer da implementação, houve mudanças, a valorização da capacidade produtiva dos alunos e liberdade em desenvolvimento dos seus próprios projetos, imersos em um ambiente lúdico. Além de uma ruptura metodológica, o cerne desse trabalho está em pensamento freiriano, o de fazer junto com as crianças e não somente levar propostas.

Já com base no construtivismo de Jean Piaget, o construcionismo de Seymour Papert e as Inteligências Múltiplas de Howard Gardner, temos Zilli (2004), que desenvolveu uma pesquisa sobre robótica educacional no Ensino Fundamental, buscando entender como se desenvolvia o trabalho de robótica educacional em quatro escolas da cidade de Curitiba que possuem robótica educacional, a partir de entrevistas com os professores que ministravam esse trabalho com robótica. Nesse grupo de escolas analisadas, o trabalho com RE era desenvolvido com alunos do $6^{\circ}$ ao $9^{\circ}$ ano do Ensino Fundamental. Em uma das instituições, fazia parte da grade curricular uma disciplina intitulada Informática Educacional; nas demais, porém, era um trabalho realizado de forma extracurricular.

O material utilizado por essas escolas era principalmente um kit denominado SuperRobby, considerado o "primeiro kit de robótica educacional projetado e fabricado no Brasil. É composto de uma interface, que funciona como um tradutor entre o micro e os diversos dispositivos a ela conectados, como motores, sensores e lâmpadas" (ZILLI, 2004, p. 45, grifo nosso). Havia a presença nas escolas de outros kits de robótica, tendo, por exemplo, o kit da LEGO ${ }^{\circledR}$ Education em duas escolas. A linguagem de programação mais utilizada foi a LOGO, desenvolvida por Seymour Papert.

Dessa investigação, Zilli (2004) propôs um modelo de constituição de sala de robótica educacional para a época, além de concluir que o trabalho com robótica é um projeto interdisciplinar e é importante que tenha a integração de diferentes áreas do conhecimento no desenvolvimento e execução de projetos nessa área. A sugestão da composição da equipe, segundo a pesquisadora, poderia ser: um professor de Artes, um de Ciências ou Matemática e uma pessoa especializada em Informática para o suporte técnico necessário. Essa configuração se baseia na seguinte argumentação: a importância do professor de Artes estaria em orientações de design e construção de protótipos; de Ciências, em explicar sobre ligações elétricas, funcionamento dos dispositivos eletrônicos; e do professor de Matemática, na questão da lógica, da programação. No que diz respeito ao kit, fica a cargo das instituições e do que elas podem comprar. $\mathrm{Na}$ execução das atividades, é uma sugestão que sejam extracurriculares, tendo tempo próprio para execução, tornando sua implementação mais fácil na escola, criando horários exclusivos para esse trabalho, que não irão conflitar com as disciplinas da grade curricular, além de garantir que somente participem os alunos que realmente tenham interesse. Seu enfoque foi na formação de uma metodologia.

Já no campo de Educação Matemática, há o trabalho de Accioli (2005), com 
formação em Engenharia. Ela ministrou aulas de programação em um período de sua carreira, o que a aproximou de projetos de ensino e aprendizagem que envolviam o uso de computadores. Durante suas investigações e elaboração de práticas que relacionassem as tecnologias às áreas de conhecimento científico, ela planejou e ministrou oficinas de robótica com uso de kits de robótica da LEGO ${ }^{\circledR}$ Education. Inicialmente, sua experiência com robótica foi em um âmbito mais lúdico e motivador aos alunos. Esse resultado fez com que ela desenvolvesse posteriormente uma pesquisa de mestrado buscando responder: como "Um ambiente de robótica pode funcionar como um micromundo de aprendizagem matemática, no sentido de possibilitar a construção de novos significados para a Simetria?" (ACCIOLI, 2005, p. 5).

A pesquisadora, ao realizar uma abordagem de micromundo, está se referindo essencialmente a um ambiente de aprendizagem baseado no computador (CBLE Computer Based Learning Environments). O micromundo em sua pesquisa é o "Sistema Robótico LEGO Dacta - ROBOLAB MINDSTORM", composto por dispositivos mecânicos e eletrônicos e uma linguagem de programação. Seu público foi composto por dois grupos de alunos do Ensino Fundamental que contemplavam alunos do $4^{\circ}$ ao $8^{\circ}$ anos de uma escola particular em atividades extracurriculares. Para esses grupos, foram elaboradas atividades, mas somente após um estudo realizado com outras três escolas, que desenvolveram oficinas de robótica no Ensino Fundamental e Médio, com enfoques em tecnologia, lúdico e conhecimentos em mecatrônica. Após análise dos resultados dessas oficinas, foi elaborado um conjunto de 10 sessões que abordavam desde a familiarização do kit com montagem livre, programação no ambiente ROBOLAB até a elaboração de um modelo de robô que realizasse uma coreografia ou, como a pesquisadora definiu, "Dança dos robôs", buscando relacionar o conceito de simetria nessa pesquisa. Assim, a partir da interação dos alunos com objetos construídos, o software de programação e os desafios propostos, as conexões com a Matemática eram estabelecidas.

Campos (2005), embasado nas teorias de aprendizagem de Jean Piaget e Seymor Papert, fundamentou sua pesquisa em uma busca para responder à seguinte questão: "Quais as contribuições da implementação de um projeto de robótica educativa no processo de ensino-aprendizagem no Ensino Fundamental?" (CAMPOS, 2005, p. 17). Nessa investigação, seu olhar de pesquisa foi mais especificamente no currículo do Ensino Fundamental I e II de uma escola particular do Estado de São Paulo.

A instituição já tinha um histórico, "onde os professores procuram desenvolver projetos de integração entre as disciplinas incluindo-os em eventos culturais que acontecem durante o ano letivo" (CAMPOS, 2005, p. 94). Referindo-se à robótica educacional, o pesquisador foi um dos responsáveis por, em 2003, introduzir e coordenar o projeto de trabalho através do material Knex ${ }^{5}$. Outros kits como da LEGO® Education também foram utilizados. Em diálogo com o corpo docente da escola, o projeto-piloto foi iniciado em uma feira científica com alunos do Ensino Médio. Nesse processo, os professores ficaram responsáveis "por integrar projetos relacionados com os conteúdos curriculares trabalhados em sala e a possibilidade de usar a robótica para demonstrá-los"

5 Esse material é importado dos Estados Unidos e é basicamente formado por dois tipos de peças: eixos e conectores. O material é comumente chamado de robótica estrutural por se tratar de um material que pode desenvolver grandes estruturas, tanto rígidas quanto flexíveis. Além dos eixos e conectores, temos também motores, polias, elásticos, pneus, engrenagens e outros acessórios que também fazem parte do material (CAMPOS, 2005, p. 95). 
(CAMPOS, 2005, p. 96). Durante a exposição, os alunos explicavam as aplicações teóricas presentes nos seus projetos (máquinas simples, transportes, força, energia e movimento, pontes, energia renovável, parque de diversão, pneumática, conceitos matemáticos e Big Ball Factory).

O projeto de robótica da escola foi construído em consonância com o currículo. Criou-se o espaço e o apoio técnico, e os projetos desenvolvidos levavam em consideração três aspectos: "Os conteúdos curriculares, conceitos científico-tecnológicos e Situação-problema/desafio" (CAMPOS, 2005, p. 117). Com base nas necessidades curriculares de cada professor, o projeto de robótica era construído, desde a montagem aos desafios que os alunos iriam executar. Essa decisão estava relacionada à compreensão do grupo de professores de que os conceitos científico-tecnológicos estão inseridos na robótica. Assim, era importante que houvesse integração dos conteúdos na robótica.

O trabalho de Oliveira (2007, p. 50) usa o termo robótica pedagógica, cuja definição é dada como "a atividade de montagem e programação de robôs, com a intenção de explorar e vivenciar aprendizagens", e, embasado nas teorias de Jean Piaget e Vygotsky sobre aprendizagem, desenvolveu sua pesquisa com alunos do ensino fundamental de uma escola particular. A justificativa dessa base teórica residia na interpretação de que ambos os pensadores "atribuem especial importância ao aspecto do comportamento do indivíduo, no que concerne ao modo como modificam a realidade e são, por ela, modificados" (OLIVEIRA, 2007, p. 30).

Sua pesquisa procurou "construir um universo que possibilitasse a elaboração de uma tese sobre robótica pedagógica, mais precisamente, sobre os possíveis movimentos intelectuais que a robótica pode oferecer na construção do conhecimento" (OLIVEIRA, 2007, p. 18). Nesse processo, uma atenção foi dada para como a criança reagia na resolução de problemas na robótica. O pesquisador descreve que a pesquisa com as crianças foi realizada em três etapas:

No $1^{\circ}$ experimento, que denominamos $A$ construção do conceito de robótica por crianças, procuramos complementar os estudos de Turkle (1989) que se concentraram no uso do computador. Utilizamos o método clínico e entrevistamos individualmente alunos do ensino fundamental. No $2^{\circ}$ experimento, desejávamos observar como a criança, em atividades de robótica, explica o que aprendeu. Então apresentávamos a uma criança, passo a passo, a montagem e programação de um pequeno robô e, logo a seguir, a mesma ensinava a um outro colega o que havia aprendido. No $3^{\circ}$ experimento, A tomada de consciência, desejávamos observar quando, como e em que grau se verificava a atuação do sujeito no estágio operatório formal Ca a seu (Sic) (OLIVEIRA, 2007, p. 17).

Esta pesquisa é fortemente embasada na teoria de Piaget em um contexto da robótica educacional. Ela tem um olhar sobre o sujeito e objeto, e a robótica se revela com uma riqueza na relação sujeito-objeto, como raras vezes encontramos em outras atividades pedagógicas (OLIVEIRA, 2007). Seu trabalho aponta uma vertente de colocar o sujeito em diferentes papéis, ou seja, além de aluno, monitor e até professor de outras crianças.

Seguindo as produções, temos Fortes (2007), que desenvolveu uma dissertação de mestrado na área de Educação Matemática sobre o trabalho com robótica educacional. $O$ 
tema já fazia parte de sua história. Enquanto educadora, foi professora de um laboratório de robótica, o qual considerou como um ambiente de aprendizagem. A motivação a aprender mais sobre robótica veio após ter trabalhado na divisão educacional da LEGO no Brasil e ao concluir sua graduação em Matemática, tanto que buscou especializações no campo da Engenharia, que foram insuficientes.

Em sua pesquisa, buscou identificar possíveis evidências, bem como potencialidades do material que seria utilizado posteriormente (FORTES, 2007, p. 3). A partir de estudos de pesquisas já existentes, como, por exemplo, Estudo de Impacto Educacional dos Materiais da LEGO, feitos pelo próprio Seymour Papert no Peru, a pesquisadora traçou como principal objetivo de sua pesquisa investigar

o impacto de um ambiente de aprendizagem robótico nas estratégias e representações usadas por estudantes de $8^{\mathrm{a}}$ série do Ensino Fundamental e $1^{0}$ ano do Ensino Médio na interpretação de gráficos apresentando relações entre distância, tempo e velocidade (FORTES, 2007, p. 5).

Ela realizou experimentos com os alunos, envolvendo produção de protótipos de robótica para trabalhar com gráficos. Nesse protótipo, feito com kit de robótica da LEGO, estavam carrinhos e um radar. Fortes $(2007$, p. 90$)$ salienta que

As atividades desenvolvidas foram baseadas no construcionismo, em que o professor estimula os alunos a desenvolverem suas próprias criações, teorias, conjecturas, por meio de desafios que incentivem os alunos a serem criativos e autônomos, aliados ao desenvolvimento de outras habilidades.

Além disso, um detalhe interessante das considerações finais, levantado na pesquisa a partir dos dados e nas reflexões da pesquisadora, dizia que o ambiente de robótica possibilita a "manipulação de diversas representações e possibilita criar relacionamentos entre tais representações" (FORTES, 2007, p. 96). Até então, essa é a primeira pesquisa que se lê que aponta esse resultado, o qual pode ser considerado um novo viés para se pesquisar.

O ano de 2007 foi bem produtivo para pesquisas na área de robótica educacional. Labegalini (2007) desenvolveu uma pesquisa participante dentro do "Projeto Criatividade" - que foi criado em uma parceria da PUC do Paraná com a Secretaria Municipal de Educação (SME) - para auxiliar o professor na integração gradativa às tecnologias em sua prática docente. Dentre as tecnologias, a pesquisadora analisou como se deu a inserção do LEGO/Robótica na prática do professor. Essa intencionalidade deve-se a dados da Secretaria Municipal de Educação (SME) sobre como se desenvolveu o incentivo à inserção de tecnologias na escola, do processo de formação dos professores e dados quantitativos apontando uma grande procura de professores pelos cursos de formação continuada. Destaca ainda que, apesar da presença de kits de robótica nas escolas municipais, um resultado indicava que poucos professores se aventuravam a aplicar o que aprenderam, por falta de segurança.

Assim, a pesquisa partiu da questão: "Como as sugestões propostas na Revista de Educação Tecnológica Zoom podem ser inseridas na sala de aula das escolas da rede pública quando da utilização do LEGO/Robótica?" (LABEGALINI, 2007, p. 19). Para 
respondê-la, foi necessário verificar em que medida as sugestões disponíveis na Revista de Educação Tecnológica Zoom são utilizadas na sala de aula, abordando estratégias metodológicas da revista, relação com a prática da sala de aula, nos cursos de formação, além de aspectos motivadores de integração LEGO/Robótica na sala de aula e nos cursos de formação.

Um aspecto que chamou nossa atenção foi a visão da pesquisadora quanto à robótica. LEGO/Robótica, para Labegalini (2007), também é vista como uma ferramenta ou tecnologia educacional que pode aproximar o aluno de sua realidade. Tanto que sua fundamentação teórica foi embasada em Seymour Papert e Armando Valente, entre outros, discutindo as tecnologias de forma geral até o contexto educacional.

Ao construir os dados de sua pesquisa, desenvolvendo o curso de formação e acompanhando da prática de um grupo de professores e seus depoimentos, concluiu-se "que a Revista Lego Zoom não foi integralmente trabalhada com os alunos" (LABEGALINI, 2007, p. 129). Além disso, afirma "que não há uma disposição por parte destes educadores para inovar o seu processo de ensino/aprendizagem" (LABEGALINI, 2007, p. 129).

As revistas são importantes para o ensino de LEGO/Robótica e podem ser inseridas em todas as escolas da rede pública, desde que os professores mostrem-se um pouco mais dispostos a trabalhar com elas (LABEGALINI, 2007, p. 128). A responsabilidade de construção de um ambiente de aprendizagem nessa pesquisa recai sobre os professores e alunos. Em termos de tecnologias e recursos, o sistema educacional tinha boa estrutura, as revistas de robótica poderiam ter sido melhor aproveitadas, mas faltou empenho dos professores, como, por exemplo, seguir as sugestões da revista. Em síntese, pode-se agrupar essa pesquisa em um conjunto de trabalhos relacionados à formação de educadores.

Já Lopes (2008) realizou sua pesquisa com alunos das séries iniciais de uma escola pública, utilizando materiais de robótica da LEGO, sendo um desses materiais desenvolvidos especialmente para se trabalhar com o projeto UCA (Um Computador por Aluno), do qual a escola fazia parte. Assim, a pesquisa ocorreu dentro do contexto que procurou "explicitar os processos cognitivos envolvidos no contexto de desenvolvimento de projetos em robótica educacional por crianças em idade escolar" (LOPES, 2008, p. 19). Considerando o potencial da robótica educacional para motivar e despertar a criatividade e o interesse pela descoberta, construiu sua pesquisa, em quatro etapas, que envolvia construção a partir de modelos, projetos temáticos, projetos voltados a campeonatos e montagens livres. Toda sua pesquisa teve um olhar sobre o aluno, em como, explorando modelos, ele podia construir condutas cognitivas que dessem suporte a construções criativas (LOPES, 2008, p. 53). Em termos de modelos, o pesquisador se referia aos protótipos propostos, à construção de programação, aos robôs construídos, e em seus dados poder-se-ia reconhecer a presença de trabalho com modelos matemáticos. A respeito disso, ele constatou que

um modelo eficiente no que se refere à possibilidade de construções criativas, seria um modelo apresentado na sua forma incompleta ou parcial, pois a constatação de um bug exige que os erros sejam compensados, provocando o reflexionamento e a consequente transformação das ações e de seus significados. (LOPES, 2008, p. 170). 
Nas considerações finais sobre seu trabalho, há uma afirmação positiva da robótica educacional construtivista como um recurso inovador às práticas pedagógicas, além disso, um elemento que chamou a atenção foi a referência à produção de projetos de pesquisa que resgatam, segundo Lopes (2008), uma dimensão do fazer em relação à construção do saber.

O trabalho de Lopes (2008) teve um foco no qual é possível englobar um conjunto de trabalhos preocupados com a formação do aluno. Da mesma forma, tem-se o trabalho de Santana (2009), que realizou uma investigação, buscando entender como crianças da $4^{a}$ série ( $5^{\circ}$ ano) aprendem e trabalham com ciência e tecnologia em um ambiente lúdico de robótica. A pesquisa é uma continuação de seu mestrado em uma perspectiva e ambiente diferentes, ou seja, ocorreu em uma instituição pública na Bahia que tinha em seu currículo robótica educacional com kits da LEGO $®$ Education.

A composição de seu trabalho perpassa uma descrição de um grande projeto de implantação da robótica na rede pública baiana usando kits da LEGO. Nesse sentido, ela descreve alguns fatos de como e onde ocorreu a implantação e alguns dos resultados. Nessa descrição, houve um trabalho com os professores, um momento de construir e reconhecer, nos materiais que lhes foram disponibilizados, os conhecimentos científicos relacionados, presentes nos projetos de montagens sugeridos pelo material de robótica. Podemos dizer que foi um momento de analisar os kits e refletir sobre suas possibilidades de trabalho na sala de aula.

Além desse momento com os educadores, Santana (2009) realizou um trabalho com crianças de uma escola, trabalhando a iniciação científica a partir de projetos e desafios. Os alunos construíram montagens e essas eram exploradas pelo professor, buscando emergir conceitos científicos. Essa pesquisa chegou a considerações de que a implantação de robótica pedagógica precisa ocorrer em etapas, preocupar-se com a formação dos professores, ter um planejamento, acompanhamento por mais tempo e a constituição de uma rede colaborativa. Foram sugestões importantes em um processo de implementação de um projeto de robótica em um ambiente escolar.

O trabalho de Santana (2009) perpassou etapas pelas quais é possível interpretar que sua pesquisa se enquadra em um conjunto de pesquisas preocupadas com a formação do aluno. Mas, nesse processo, ela percorreu todo um caminho que não desconsiderou também a formação do educador, numa condição biunívoca, em que um depende do outro.

Pensando também na formação dos alunos, há a presença do trabalho de Maliuk (2009), que desenvolveu sua dissertação sobre robótica educacional no ensino de Matemática, relatando sua experiência na rede pública de ensino de Porto Alegre com alunos do $9^{\circ}$ ano. As atividades de robótica foram desenvolvidas em conjunto com as aulas regulares de Matemática. Nesse contexto, foram desenvolvidos diferentes robôs, que participaram de um torneio de robótica, o que contribuiu para inseri-los na realidade da comunidade do bairro, conhecer um centro de reciclagem, modelar a produção de alguns resíduos e do projeto de acordo com o tema do torneio. Dessa forma, foi possível trabalhar com Matemática, desenvolver protótipos que seriam úteis para o contexto estudado, além de relacionar os conhecimentos científicos à vida. "Mas uma coisa todas elas têm em comum: para estarem abertas às diferentes possibilidades de aprendizagens, apresentaram-se sempre como Cenários de Investigação" (MALIUK, 2009, p. 77).

Seguindo uma direção diferente, há o trabalho de Silva (2009), que em sua tese de 
doutorado detectou que algumas pesquisas de robótica no Brasil colocavam a robótica como parte das ferramentas computacionais de auxílio no ensino e na aprendizagem. Ela expõe que em nenhum momento houve investigação dos aspectos metodológicos do uso de robôs como elementos mediadores da aprendizagem, muito menos com o uso da teoria histórico-cultural de Vygotsky.

Nesse sentido, Silva (2009) construiu sua pesquisa procurando contribuir com o desenvolvimento de uma metodologia de ensino-aprendizagem baseada na teoria sóciohistórica de Vygotsky para aplicação de robótica, como ferramenta de auxílio no processo ensino-aprendizagem em escolas do ensino fundamental (SILVA, 2009, p. 3). Assim, para construir sua metodologia, foi desenvolvido um sistema denominado RoboEduc, constituído de peças, de software e de uma metodologia que busque valorizar as interações sociais dos sujeitos envolvidos na pesquisa, que ela definiu como sendo os alunos, professores e robôs.

Para trabalhar o sistema RoboEduc, a pesquisadora, juntamente com o laboratório NATALNET da Universidade Federal do Rio Grande do Norte, desenvolveu a pesquisa por meio do "Projeto Inclusão Digital com Robô" com alunos de $4^{\circ}$ e $5^{\circ}$ anos de uma escola municipal e periférica da cidade de Natal, usando informações da Secretaria da Educação da cidade como critério de escolha da instituição - que a caracterizava como escolamodelo - e dados da Fundação Getúlio Vargas sobre o mapa de exclusão digital do Brasil.

Assim, RoboEduc tinha sua constituição de hardware, ou seja, kits de robótica da LEGO ${ }^{\circledR}$ Mindstorms RCX, um software também com o nome RoboEduc que possui níveis de uso, com tutoriais, controle e programação dos robôs. Para completar, uma metodologia de trabalho construída com diálogo com a comunidade escolar; formação de tutores; organização das oficinas que procuraram, embasadas na teoria de Vygotsky; trabalho com temas interdisciplinares, possibilitando assim o diálogo com outras áreas de conhecimento. Essa integração de conhecimentos em um mesmo ambiente com robótica, na forma de oficinas, segundo Silva (2009), residia em, a partir de um tema, construir uma sequência para a aprendizagem, através de delineamento do problema, solução e construção do problema e avaliação.

Enfim, segundo Silva (2009), com as atividades desenvolvidas em cada oficina de robótica, uma gama de conteúdos, quer sejam conceituais ou procedimentais, foram trabalhados em conjunto com as partes envolvidas no projeto de inclusão digital com robôs. Apesar da complexidade da teoria de Vygotsky e do conceito de Zona de Desenvolvimento Proximal (ZPD), pode-se concluir que a robótica também necessita de mais investigações no campo metodológico e que a metodologia obtida na pesquisa mostra-se promissora para utilização de robótica no ensino fundamental. Mesmo que a pesquisa tenha por objetivo a constituição de uma metodologia, ela não deixa de almejar a formação do educando e educador.

O trabalho de Santos (2010) desenvolveu uma pesquisa de mestrado em Ciências e Matemática, tendo como base teórica Seymour Papert, em virtude da sua importância na disseminação da robótica pelo Brasil. Sua pesquisa praticamente iniciou-se em uma disciplina da graduação com enfoque interdisciplinar, quando conheceu o tema robótica. A partir desse momento, acabou tornando-se tema de sua pesquisa de mestrado. A pesquisa procurou responder algumas questões, como: 
Como discutir conceitos científicos por meio da robótica em um ambiente colaborativo? Que características oriundas do lúdico estão presentes na robótica educacional? Como pode ser efetivada a relação entre a robótica educacional e o lúdico em sala de aula para a construção de conceitos e motivação dos alunos do ensino médio? (SANTOS, 2010, p. 3).

Como pode-se perceber, as inquietações do pesquisador estavam na relação da robótica ser uma área de interação homem e máquina (SANTOS, 2010) e ser capaz de discutir conceitos científicos e explorar a questão lúdica presente na robótica. Essas intencionalidades de sua pesquisa foram discutidas e levantadas em uma escola pública de ensino médio em que era professor de Matemática. Suas atividades de robótica aconteceram com alunos voluntários do $3^{\circ}$ ano do ensino médio, no espaço da escola, utilizando o laboratório de informática, por cerca de duas horas, aos sábados pela manhã.

A partir de temas propostos pelos alunos: "uma aranha mecânica, uma casa giratória, um carro de brinquedo, um prédio com mecanismos de elevador e iluminação em um parque de diversão" (SANTOS, 2010, p. 39), foram trabalhados conceitos científicos e a tecnologia. Como recursos para implementação dos projetos, foram utilizados uma placa denominada XPLUS da CERNE tecnologia e o software o MegaLOGO.

Os resultados da pesquisa permitiram perceber que foi possível nos trabalhos desenvolvidos, no que se refere aos projetos de robótica, trabalhar com

\begin{abstract}
conceitos de geometria e de energia, conteúdos referentes à Matemática e Física trouxeram aos alunos uma forma concreta de se ver o que é ensinado em sala de aula, isto é, uma nova moral epistemológica na educação. Esses aspectos se mostraram mais fortes na construção dos protótipos, que por sua vez na execução apresentou fortemente algumas características de lúdico como: interesse e motivação, competição, discussão conceitual (SANTOS, 2010, p. 78).
\end{abstract}

Assim, a pesquisa permitiu construir uma relação dos conhecimentos científicos, utilizando-se de tecnologia, de robótica, para desenvolver projetos a partir de temas relacionados com as intenções da robótica educacional, quando se pensa em promover a "integração de disciplinas e observando que os alunos podem vivenciar na prática o método científico através da simulação de protótipos" (SANTOS, 2010, p. 12-13), sem se esquecer da questão lúdica incorporada à robótica. Em síntese, entende-se que a pesquisa faz parte de um conjunto cuja vertente é a formação dos educandos ou alunos.

Leitão (2010), também sustentado pela teoria de Seymour Papert, desenvolveu sua pesquisa com alunos do ensino fundamental de uma escola particular, aplicando uma metodologia de design experiment que requer uma sequência de episódios. Sua pesquisa tinha como objetivo "investigar as potencialidades e contribuições que a utilização da robótica educacional oferece para o ensino da Matemática" (LEITÃO, 2010, p. 11). Novamente, há um trabalho com enfoque na formação dos alunos.

A sequência de atividades construídas com os alunos partia de trabalhos que instruíam sobre o kit, funcionamento e controle do robô utilizando-se de desafio. Como atividade final, houve um desafio que envolvia a coreografia ou dança de robôs. Nessa atividade, o pesquisador, que utiliza muito do termo emergir, revela que ocorreu a mobilização de várias ideias matemáticas, como simetria e reflexão, estimativa, 
proporcionalidade e propriedades de ângulos. Em suas considerações finais, o autor afirma que, nas circunstâncias nas quais ocorreu a pesquisa, "a matemática emerge com certa naturalidade" (LEITÃO, 2010, p. 82).

Outro trabalho com aporte teórico, o construcionismo de Papert, foi de Furletti (2010), que ocorreu em uma escola particular de Belo Horizonte, com todos os alunos regularmente matriculados no segundo ano do ensino médio. O pesquisador era também o professor de Matemática da turma e tinha incluído a robótica em suas aulas. Essas, foram ministradas em um laboratório de robótica, onde ele desenvolveu a maior parte da pesquisa, deixando a exploração matemática para a sala de aula. Sua pesquisa teve como tema principal a "exploração de tópicos matemáticos em modelos robóticos com utilização da linguagem LOGO no Ensino Médio" (FURLETTI, 2010, p. 11). Para tal, foi desenvolvido um estudo sobre a construção de uma roda-gigante nos seguintes passos:

\begin{abstract}
A sequência se inicia com a construção da roda-gigante, depois para o funcionamento é necessário a sua programação, após o domínio da programação os estudantes realizam duas atividades abordando conceitos de funções do primeiro e segundo grau, essas últimas duas atividades podem ser agregadas ao conteúdo de sistemas lineares, dependendo do nível de conhecimento dos envolvidos (FURLETTI, 2010, p. 58).
\end{abstract}

Assim, "as conclusões da pesquisa convergem de forma favorável à manipulação de modelos robóticos como ferramenta auxiliar no ensino de conceitos matemáticos" (FURLETTI, 2010, p. 92). O centro da pesquisa estava em relacionar os conhecimentos matemáticos com o uso da tecnologia robótica, mostrar sua potencialidade em um efeito pedagógico de ensino e aprendizagem da Matemática. Em outras palavras, o personagem principal não é o aluno, mas os conhecimentos matemáticos construídos com a robótica. Assim sendo, mesmo usando da formação dos educandos, a direção do seu trabalho é um enfoque metodológico.

Como último trabalho de 2010, temos o de Moraes (2010), que levantou e discutiu as potencialidades da robótica no ensino, especialmente de Matemática. Durante sua formação continuada, a escola particular em que atuava adotou em seu Projeto Pedagógico a Robótica Educacional com uso de kits da LEGO. Isso deve-se ao reconhecimento que o modelo educacional da LEGO proporciona, possibilidade de ter uma aprendizagem em que o aluno possa construir os seus conhecimentos a partir de recursos pedagógicos ou ferramentas tecnológicas (MORAES, 2010, p. 23).

A experiência da pesquisadora permitiu reconhecer na robótica um indicador da potencialidade no ensino de Matemática, trabalhando com 28 alunos do oitavo ano (antiga sétima série) do ensino fundamental, que trabalharam robótica associada com conceitos de Matemática. A robótica era trabalhada na escola com

[...] a criação e montagem de um mecanismo, utilizando o kit LEGO, com participação efetiva do professor e de seus alunos em cada etapa. No intuito de desenvolver o raciocínio lógico, é utilizado um processo de mediação entre aluno e professor, com a intenção de melhorar as funções cognitivas dos alunos. Esse processo consiste em dirigir perguntas e trabalhar respostas de modo a desenvolver, corrigir ou aprimorar essas funções cognitivas, buscando a interação entre os sujeitos em aprendizagem (MORAES, 2010, p. 28). 
Para Moraes a utilização da robótica educacional favorece a criação de novas dinâmicas na sala de aula, de ambientes que estimulam a discussão e a troca de ideias, que incentivam a formulação das aprendizagens matemáticas (MORAES, 2010, p. 61). As investigações se deram com três experimentos: Balança de dois pratos, Robô Girafa e Ponte Levadiça, que permitiram explorar formas geométricas e equação de primeiro grau.

Todo o trabalho envolvendo saberes e práticas em sala de aula permitiu a Moraes registrar e observar na prática as potencialidades que a Robótica Educacional pode propiciar ao ensino de Ciências e Matemática, principalmente "nas aprendizagens matemáticas, visto que estas foram fortemente destacadas, quando relacionado 0 conteúdo matemático com as atividades realizadas na sala da robótica" (MORAES, 2010, p. 106).

Agora em 2011, pensando na formação dos alunos, foi publicada e defendida a dissertação de Barbosa (2011), no mestrado em educação, em um contexto da educação pública em uma escola periférica da cidade de Uberlândia. A questão de pesquisa foi: "Como o trabalho com robótica educacional possibilita a constituição de um ambiente de aprendizagem significativo no contexto da escola pública?". Buscando responder essa questão, o pesquisador utilizou da análise da trajetória de organização do trabalho educativo com robótica, atentando para a constituição de cenários de práticas pedagógicas com robótica educacional, resultantes da interação humana.

A pesquisa ocorreu em uma escola pública, com alunos do $9^{\circ}$ ano do ensino fundamental, durante o contraturno de suas atividades regulares, uma vez por semana, com acompanhamento de uma professora de Matemática e outra de Informática. Para o desenvolvimento das atividades, utilizou-se o laboratório de informática da escola como principal espaço de produção e encontro. Durante cerca de um ano e meio, houve visitas à escola, desenvolvendo, assim, atividades de robótica, subsidiadas por instituições de fomento à pesquisa ${ }^{6}$. A cada semestre, novas turmas de alunos eram formadas, a fim de contemplar o máximo de interessados em fazer parte das atividades de robótica.

As atividades inicialmente eram com sucata ou eletrônicos em desuso, mas durante alguns momentos da pesquisa foi possível trabalhar com um kit de robótica da LEGO ${ }^{\circledR}$ Education. A construção das atividades buscava sempre fazer uso do computador e da internet para o desenvolvimento de pesquisa, recurso de registro de dados, orientação e estímulo a uma autonomia produtiva através dos blogs, softwares e rede social ${ }^{7}$. Além disso, era um espaço público, no qual todos os alunos poderiam ver as dúvidas dos colegas e aprender em comunhão. Poderia haver o desenvolvimento de um espaço virtual como um fórum, mas escolheu-se usar o recurso do blog com essa mesma finalidade, pois era um espaço integrado com atividades, dúvidas, reflexões e soluções.

$\mathrm{O}$ ambiente de aprendizagem com robótica girava em torno de projetos, sendo o ponto de partida um artefato, e dele desdobravam-se estudos sobre sua construção, buscando explorar a Matemática nele e em seu uso. Os projetos desenvolvidos foram em torno dos seguintes artefatos robóticos: Beetlebot e Catapulta. No processo de trabalho, uma iniciativa adotada foi a seleção de monitores entre os alunos da robótica, possibilitando que jovens ensinassem seus colegas. Por mais que a iniciativa estivesse na

6 Fundação de Amparo à Pesquisa de Minas Gerais (FAPEMIG) e Pró-reitoria de Extensão, Cultura e Assuntos Estudantis da Universidade Federal de Uberlândia (PROEX).

7 A rede social utilizada era a chamada Orkut, a mais popular no de 2010, quando ocorreu a pesquisa. 
formação de educandos, o trabalho encaixava-se em uma metodologia de trabalho.

Barros (2011) realiza uma pesquisa com software RoboEduc em sua versão mais recente, já que esse mesmo software foi analisado e desenvolvido em Silva (2009). Há também Souza (2011), que desenvolveu uma pesquisa pensando na educação a distância, na robótica, nos avanços tecnológicos de comunicação e na possibilidade de se desenvolver e construir um ambiente telerrobótico de forma que mesmo a distância possa-se interagir com o robô. Essa terminologia de telerrobótica foi utilizada em 2002 por Marco Tulio Chella. Tanto Barros (2011) como Souza (2011) dão enfoque em metodologia.

No ano seguinte, há o trabalho de César (2013), que deu continuidade à sua dissertação de 2009, desenvolvendo uma tese de doutorado a partir da análise de oficinas sobre robótica pedagógica livre: UNEB (Salvador/BA) - 2009/2010 e Universidad de la República/UY (Taller de Arte y Programación - TAP) - 2010. Na tese, esses foram os espaços principais analisados, mas outras cinco oficinas foram construídas em outros espaços, a fim de desenvolver uma metodologia de difusão do conhecimento sobre/para robótica pedagógica livre (RPL). Para tanto, desenvolveu oficinas, trabalhando com 171 educandos (43 mulheres, 118 homens e 10 não quiseram se identificar), com idades entre 15 e 50 anos, de diferentes áreas de conhecimento (CÉSAR, 2013, p. 104).

Em sua pesquisa com robótica pedagógica livre, termo usado desde o mestrado por trabalhar com sucata eletrônica, César (2013) construiu e analisou seus dados através de um Espaço Multirreferencial de Aprendizagem (EMA), o que, segundo o pesquisador, significa que a aprendizagem pode ocorrer em diferentes espaços além da escola. Assim, a construção da robótica pedagógica livre busca o desenvolvimento de

\footnotetext{
um modelo de espaço multirreferencial de aprendizagem com o uso de soluções livres e utilizando-se artefatos robóticos para se apropriar dos conceitos de produção e desenvolvimento de ideias, modelos e conhecimentos, o que vai além do mero consumo de informações e soluções produzidas em escolas, faculdades e universidades (CÉSAR, 2013, p. 45).
}

O termo "artefatos robóticos" na tese ganha um novo significado e nome, passando a ser artefato cognitivo o objeto técnico que possibilita e auxilia as/nas experiências vivenciadas no processo de aprendizagem e desenvolvimento cognitivo, a partir de sua interação subjetiva e singular com os seres humanos (CÉSAR, 2013).

A construção de artefatos cognitivos fez parte da oficina. Além de momentos teóricos, teve o momento prático, quando os educandos puderam construir seus robôs, montando um kit com materiais para robótica pedagógica livre. Toda essa pesquisa usou registros em espaços virtuais, depoimentos e vídeos para registrar os dados. A análise desses dados permitiu inferir, em uma de suas conclusões, que a importância desse trabalho ocorre em dois momentos, da apropriação do conhecimento e da multiplicação, ou seja, a informação é compartilhada livre, um fundamento defendido por César (2013).

\section{Considerações finais}

Há a certeza de que outros trabalhos foram construídos, mas é impossível 
apropriar-se de todos. À medida que a popularização e o trabalho com robótica no contexto educacional crescem, resultados começam a surgir. Nessa revisão, contemplaram-se alguns trabalhos publicados nos últimos 16 anos, encontrados em repositórios online, como a Biblioteca Nacional e Banco de teses e dissertações da Capes. A partir dessas investigações, produziu-se um mapeamento das pesquisas sobre robótica educacional (Quadro 1), com trabalhos de pesquisa que dizem onde, como, quando e com quem se tem construído pesquisas com robótica.

Quadro 1: Relação das dissertações e teses analisadas em relação às universidades no decorrer dos anos.

\begin{tabular}{|c|c|c|c|c|c|c|c|c|c|c|c|c|c|}
\hline Regiones & Ins. Ens. Superior / Ano & 2002 & 2003 & 2004 & 2005 & 2006 & 2007 & 2008 & 2009 & 2010 & 2011 & 2012 & 2013 \\
\hline NORTE & Universidade Federal do Amazonas & & & & & & & & & & SOUZA & & \\
\hline \multirow{2}{*}{ NORDESTE } & Universidade Federal do Rio Grande do Norte & & & & & & & & SILVA & & BARROS & AROCA & \\
\hline & Universidade Federal da Bahia & & SANTANA & & & & & & SANTANA;CÉSAR & & SILVA & & CÉSAR \\
\hline CENTRO - OESTE & Universidade Federal de Goiás & & & & & & & & & SANTOS & & & \\
\hline \multirow{10}{*}{ SUDESTE } & Universidade Estadual de Campinas & CHELLA & & & & & & & & & & & \\
\hline & Universidade de São Paulo & STEFFEN & & & & & & & & & & & \\
\hline & Universidade Vale do Rio Verde de Três Coraçōes & & & PEREIRA & & & & & & & & & \\
\hline & Universidade Presbiteriana Mackenzie & & & & CAMPOS & & & & & & & & \\
\hline & \begin{tabular}{|l|} 
Centro Federal de Educação Tecnológica de Minas \\
Gerais \\
\end{tabular} & & & & & ROCHA & & & & & & & \\
\hline & Pontificia Universidade Católica de São Paulo (PUC.SP) & & & & & & FORTES & & & & & & \\
\hline & Instituto de Tecnologia para o Desenvolimento - LACTEC & & & & & & & CURCIO & & & & & \\
\hline & Pontificia Universidade Católica de Minas & & & & & & & & & FURLETTI & & & \\
\hline & \begin{tabular}{|l} 
Universidade Federal do Rio de Janeiro \\
\end{tabular} & & & & & & & & & & PINTO & & \\
\hline & Universidade Federal de Uberlândia - UFU & & & & & & & & & & BARBOSA & & \\
\hline \multirow{6}{*}{ SUL } & Universidade Federal de Santa Catarina & & ORTOLAN & ZIILLI & & & & & & & & & \\
\hline & Pontificia Universidade Católica do Rio Grande do Sul & & & & & SANTOS & & & & & & & \\
\hline & Universidade Federal do Rio Grande do Sul & & & & & & OLIVEIRA & LOPES & MALIUK & & & & \\
\hline & \begin{tabular}{|l|} 
Pontificia Universidade Católica do Paraná \\
\end{tabular} & & & & & & LABEGALINI & & & & & & \\
\hline & \begin{tabular}{|l} 
Universidade Estadual de Maringá \\
\end{tabular} & & & & & & GONÇALVES & & & & & & \\
\hline & FURG-Universidade Federal do Rio Grande & & & & & & & & & MORAIS & & & \\
\hline
\end{tabular}

Fonte: Barbosa (2016, p. 79).

Como podemos ver no quadro, a produção de pesquisa em Robótica Educacional no país teve uma grande concentração na região sudeste, sendo a partir de 2007 um crescimento na região sul e nordeste. As pesquisas nesse campo têm crescido por todo país, se desenvolvendo em diferentes perspectivas e, por isso, representando a diversidade dos lugares, pessoas e materiais disponíveis. Isso amplia e enriquece a produção científica, favorecendo todos os pesquisadores que estão iniciando ou já fazendo pesquisa há algum tempo, pois acelera as investigações em múltiplas direções e com diferentes recursos.

Após analisar as dissertações e teses disponíveis, foi possível elencar alguns conceitos que se referem à Robótica Educacional: ambiente, ambiente de aprendizagem, recurso de comunicação, tecnologia, artefato cognitivo, atividade de montagem, conjunto de recursos, espaços multirreferenciais de aprendizagem.

Eles são teias de uma rede que sustenta outros dois conceitos principais: educacional e pedagógica. Esses dois conceitos entrelaçados ao termo "robótica" geram, no mínimo, duas ideias poderosas: robótica educacional e robótica pedagógica. Ideias poderosas que discutem posicionamentos ideológicos do saber científico-tecnológico: proprietários ou livres, pois trazem em seu âmago a poderosa ideia de os robôs serem objetos de pensar com. Por isso, são, também, elementos mediadores da aprendizagem que nos ensinam que os muros da escola não são limites, uma vez que o seu trabalho transpõe os espaços de aprendizagem, proporcionando cenários de: investigação, 
programação, reflexão, transformação do mundo e processos de autoria.

Assim, a característica principal dessas ideias poderosas é possibilitar os referidos cenários. Esse fato é evidenciado pelas propostas de pesquisa estudadas aqui, que, quase sempre, resultam em metodologias para ensinar e aprender, pela robótica, um novo meio de produzir saberes científico-tecnológicos nos diversos níveis da Educação.

\section{Referências}

ACCIOLI, R. M. Robótica e as Transformações Geométricas: um estudo exploratório com alunos do ensino fundamental. 2005. 223 f. Dissertação (Mestrado em Educação Matemática) - Curso de Mestrado em Educação Matemática, Pontifícia Universidade Católica de São Paulo, São Paulo, 2005.

BARBOSA, F. da C. Rede de Aprendizagem em Robótica: uma perspectiva educativa de trabalho com jovens. 2016. 367 f. Tese (Doutorado em Educação) - Programa de Pósgraduação em Educação, Universidade Federal de Uberlândia. 2016.

BARBOSA, Fernando da Costa. Educação e robótica educacional na escola pública: as artes do fazer. 2011. 182 f. Dissertação (Mestrado em Educação) - Programa de Pósgraduação em Educação, Universidade Federal de Uberlândia. 2011.

BARROS, R. P. Evolução, avaliação e validação do software RoboEduc. 2011. 92 f. Mestrado (Dissertação em Engenharia Elétrica) - Programa de Pós-graduação em Engenharia Elétrica, Universidade Federal do Rio Grande do Norte, 2011.

CAMPOS, F. R. Robótica pedagógica e inovação educacional: uma experiência no uso de novas tecnologias na sala de aula. 2005. 145 f. Dissertação (Mestrado em Educação) Universidade Presbiteriana Mackenzie, São Paulo, 2005.

CÉSAR, D. R. Potencialidades e limites da robótica pedagógica livre no processo de (re)construção de conceitos científico-tecnológicos a partir do desenvolvimento de artefatos robóticos. 2009. 135 f. Dissertação (Mestrado em Educação) - Curso de Programa de Pós-graduação em Educação, Universidade Federal da Bahia, Salvador, 2009.

CÉSAR, D. R. Robótica pedagógica livre: uma alternativa metodológica para a emancipação sociodigital e a democratização do conhecimento. 2013. 220 f. Tese (Doutorado em Difusão do Conhecimento) - Curso de Faculdade de Educação, Universidade Federal da Bahia, Salvador, 2013.

CHELLA, M. T. Ambiente de robótica para aplicações educacionais com superlogo. 2002. 186 f. Dissertação (Mestrado em Engenharia Elétrica e de Computação) - Curso de Faculdade de Engenharia Elétrica e de Computação, Universidade Estadual de Campinas, Campinas, 2002. 
CURCIO, C. P. de C. Proposta de método de robótica educacional de baixo custo. 2008. 101 f. Dissertação (Mestrado em Desenvolvimento de Tecnologia) - Curso de Programa de Pós-Graduação em Desenvolvimento de Tecnologia, Instituto de Tecnologia para o Desenvolvimento - Lactec, Curitiba, 2008.

FORTES, R. M. Interpretação de gráficos de velocidade em um ambiente robótico. 2007. 121 f. Dissertação (Mestrado em Educação Matemática) - Curso de Mestrado em Educação Matemática, Pontifícia Universidade Católica de São Paulo, São Paulo, 2007.

FURLETTI, S. Exploração de tópicos de Matemática em modelos robóticos com utilização do software Slogo no Ensino Médio. 2010. 134 f. Dissertação (Mestrado) - Curso de Mestrado em Ensino de Ciências e Matemática, Pontifícia Universidade Católica de Minas Gerais, Belo Horizonte, 2010.

GONÇALVES, P. C. Protótipo de um robô móvel de baixo custo para uso educacional. 2007. 86 f. Dissertação (Mestrado em Ciência da Computação) - Curso de PósGraduação em Ciência da Computação, Universidade Estadual de Maringá, Maringá, 2007.

LABEGALINI, A. C. A construção da prática pedagógica do professor: o uso do Lego/robótica na sala de aula. 2007. 124 f. Dissertação (Mestrado em Educação) - Curso de Mestrado em Educação, Pontifícia Universidade Católica do Paraná, Curitiba, 2007.

LEITÃO, R. L. A dança dos robôs: qual a matemática que emerge durante uma atividade lúdica com robótica educacional? 2010. 87 f. Dissertação (Mestrado em Educação Matemática) - Curso de Mestrado em Educação Matemática, Universidade Bandeirante de São Paulo, São Paulo, 2010.

LOPES, D. de Q. Exploração de modelos e o nível de abstração nas construções criativas com Robótica Educacional. 2008. 174 f. Tese (Doutorado em Informática na Educação) Curso de Pós-Graduação em Informática Na Educação, Universidade Federal do Rio Grande do Sul, Porto Alegre, 2008.

MALIUK, K. D. Robótica Educacional como Cenário Investigativo nas Aulas de Matemática. 2009. 91 f. Dissertação (Mestrado em Ensino de Matemática) - Curso de Programa de Pós-Graduação em Ensino de Matemática, Universidade Federal do Rio Grande do Sul, Porto Alegre, 2009.

MORAES, M. C. Robótica educacional: socializando e produzindo conhecimentos matemáticos. 2010. 144 f. Dissertação (Mestrado em Educação em Ciências) - Curso de Programa de Pós-Graduação em Educação em Ciências: Química da Vida e Saúde, Universidade Federal do Rio Grande, Rio Grande, 2010.

OLIVEIRA, J. A. C. Robótica como interface da tomada de consciência da ação e do conhecimento do objeto, através da metacognição como propulsora da produção do conhecimento. 2007. $96 \mathrm{f}$. Tese (Doutorado em Informática na Educação) - Curso de Doutorado em 
Informática na Educação, Universidade Federal do Rio Grande do Sul, Porto Alegre, 2007.

ORTOLAN, I. T. Robótica educacional: uma experiência construtiva. 2003. 157 f. Dissertação (Mestrado) - Curso de Pós-Graduação em Ciência da Computação, Universidade Federal de Santa Catarina, Florianópolis, 2003.

PAPERT, S. The Future of School. 1980. Disponível em: <http://www.papert.org/articles/freire/freirePart1.html>. Acesso em: 25 out. 2018.

PAPERT, S. A família em rede: Ultrapassando a barreira digital entre gerações. Tradução de Fernando José Silva Nunes e Fernando Augusto Bensabat Lacerda e Melo. Lisboa: Relógio D'Água Editores, 1996.

PAPERT, S. What's the big idea? Toward a pedagogy of idea power. Ibm Systems Journal. New York, p. 720-729. jun. 2000. Disponível em: <https://llk.media.mit.edu/>. Acesso em: 12 ago. 2014.

PONTES, L. A história da robótica educacional (RE). 2010. Disponível em: $<$ https://lelinopontes.wordpress.com/2010/06/25/historia-da-robotica-educacionalre/>. Acesso em: 2 fev. 2015.

ROCHA, R. Utilização da robótica pedagógica no processo de ensino aprendizagem de programação de computadores. 2006. 116 f. Dissertação (Mestrado em Educação Tecnológica) - Curso de Mestrado em Educação Tecnológica, Centro Federal e Educação Tecnológica de Minas Gerais, Belo Horizonte, 2006.

SANTANA, M. do R. P. de. Em busca de novas possibilidades pedagógicas: a introdução da robótica no currículo escolar. 2003. 260 f. Dissertação (Mestrado) - Curso de Programa de Pós-graduação em Educação, Faculdade de Educação, Universidade Federal da Bahia, Salvador, 2003.

SANTANA, M. do R. P. de. Em busca de outras possibilidades pedagógicas: "trabalhando" com ciência e tecnologia. 2009. 218 f. Tese (Doutorado em Educação) - Curso de Programa de Pós-graduação em Educação, Faculdade de Educação, Universidade Federal da Bahia, Salvador, 2009.

SANTOS, M. F. A robótica educacional e suas relações com o ludismo: por uma aprendizagem colaborativa. 2010. 99 f. Dissertação (Mestrado em Educação em Ensino de Ciências e Matemática) - Curso de Programa de Pós-Graduação em Educação em Ensino de Ciências e Matemática, Universidade Federal de Goiás, Goiânia, 2010.

SILVA, A. F. da. RoboEduc: uma metodologia de aprendizado com robótica educacional. 2009. 133 f. Dissertação (Mestrado em Ciência e Engenharia Elétrica) - Curso de Programa de Pós-Graduação em Ciência e Engenharia Elétrica, Universidade Federal do Rio Grande do Norte, Natal, 2009. 
SOUZA, M. B. de. Arcabouço de um ambiente telerrobótico baseado em sistemas multiagente. 2011. 99 f. Dissertação (Mestrado em Informática) - Programa de PósGraduação em Informática, Universidade Federal do Amazonas. 2011.

STEFFEN, H. H. Robótica pedagógica na educação: um recurso de comunicação, regulagem e cognição. 2002. 113 f. Dissertação (Mestrado em Ciências da Comunicação) - Curso de Programa de Pós-Graduação em Ciências da Comunicação, Universidade de São Paulo, São Paulo, 2002.

ZILLI, S. do R. A Robótica educacional no ensino fundamental: perspectivas e prática. 2004. 89 f. Dissertação (Mestrado em Engenharia de Produção) - Curso de Programa de Pós-Graduação em Engenharia de Produção, Universidade Federal de Santa Catarina, Florianópolis, 2004.

Recebido em dia 30 de outubro de 2018. Aprovado em dia 30 de novembro de 2018. 